\title{
Erratum to: A Qualitative Investigation of the Impact of a Livelihood Intervention on Gendered Power and Sexual Risk Behaviors Among HIV-Positive Adults in Rural Kenya
}

\author{
Jennifer M. Zakaras ${ }^{1} \cdot$ Sheri D. Weiser $^{2,3} \cdot$ Abigail M. Hatcher $^{1,4} \cdot$ Elly Weke $^{5}$. \\ Rachel L. Burger ${ }^{1}$ Craig R. Cohen ${ }^{1,3} \cdot$ Elizabeth A. Bukusi $^{5} \cdot$ Shari L. Dworkin ${ }^{3,6,7}$
}

Published online: 29 August 2016

(c) Springer Science+Business Media New York 2016

\section{Erratum to: Arch Sex Behav}

\section{DOI 10.1007/s10508-016-0828-x}

Please note that the surname of author Rachel L. Burger was misspelled (as "Berger") in this article as originally published.

Shari L. Dworkin

shari.dworkin@ucsf.edu

1 Department of Obstetrics, Gynecology and Reproductive Sciences, University of California, San Francisco, CA, USA

2 Department of Medicine, University of California, San Francisco, CA, USA

3 Center of Expertise in Women's Health and Empowerment, University of California Global Health Institute, San Francisco, CA, USA

4 Wits Reproductive Health and HIV Institute, University of the Witwatersrand, Johannesburg, South Africa

5 Centre for Microbiology Research, Kenya Medical Research Institute, Nairobi, Kenya

6 Department of Social and Behavioral Sciences, School of Nursing, University of California, San Francisco, CA, USA

7 UCSF School of Nursing, 3333 California Street, LHTS \#455, San Francisco, CA 94118, USA 